\title{
Application of ZnO nanoparticles in Self-Cleaning Coating on a Metal Panel: An Assessment of Environmental Benefits
}

Barbora Stieberova, ${ }^{1}$ Miroslav Zilka, ${ }^{1}$ Marie Ticha, ${ }^{1}$ Frantisek Freiberg, ${ }^{1}$ P. Caramazana-Gonzalez, ${ }^{2,3}$ Jon McKechnie, ${ }^{3}$ Edward Lester ${ }^{2}$

\begin{abstract}
This article is focused on assessing environmental benefits of self-cleaning coating (SCC) containing nanoparticles (NPs) applied on metal panels. ZnO NPs are incorporated in the coating to enhance the level of hydrophobicity, which enables a dramatic reduction in the need for surface maintenance. The key question evaluated in this paper is whether the overall environmental performance of nano-based SCC is better than the environmental performance of coating without NPs. Much of the paper is dedicated to a comparison of advanced polyvinylidene fluoride (PVDF) protective coating with an alternative coating in which part of the PVDF is replaced by ZnO NPs. An integral part of the paper represents a detailed environmental assessment of the key ingredient of the nano-enhanced coating, ZnO NPs produced by large-scale supercritical hydrothermal synthesis developed within the Sustainable Hydrothermal Manufacturing of Nanomaterials (SHYMAN) project. LCA results show that the coating with NPs performs better than the coating without NPs in all assessed impact categories. This is due to the elimination of environmental impacts during the use stage where no maintenance is needed in case of the coating with NPs. This reduction clearly outweighs the small additional environmental impacts of the production stage associated with the ZnO NPs.
\end{abstract}

Keywords: Life cycle assessment, self-cleaning coating, zinc oxide, nanoparticles, supercritical hydrothermal syntheses, PVDF coating

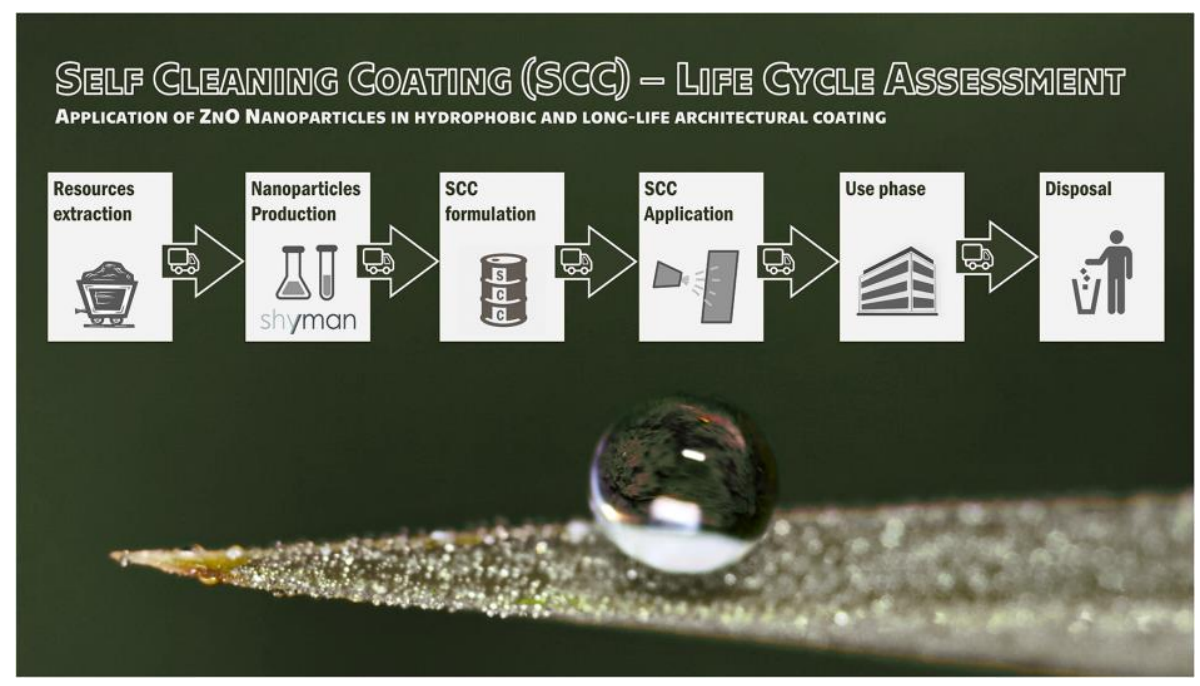

${ }^{1}$ Czech Technical University in Prague, Faculty of Mechanical Engineering, Department of Management and Economics, Karlovo namesti 13, CZ-11235 Prague 2, Czech Republic

${ }^{2}$ Advanced Materials Research Group, Faculty of Engineering, The University of Nottingham, Nottingham, NG7 2RD, UK

${ }^{3}$ Bioprocess, Environmental and Chemical Technologies, Faculty of Engineering, The University of Nottingham, Nottingham, NG7 2RD, UK 


\section{Introduction}

Recently there has been intense development in the field of nanoparticle production technologies and a rapid growth in applications of nanomaterials. For example, the number of registered nanoproducts has grown from just 54 in 2005 to 1,865 in $2013^{1}$. In efforts to produce new technologies and materials with minimal environmental impact the use of life cycle assessment (LCA) methodology at the product development stage plays an increasingly vital role.

The Sustainable Hydrothermal Manufacturing of Nanomaterials (SHYMAN) project, under the EU's Seventh Framework Programme (7FP), focuses on the development of a large-scale sustainable nanoparticle production technology, continuous supercritical hydrothermal synthesis. LCA methodology was used to assess production for different nanoparticles (NPs) as well as their final product applications.

One of the product case studies was the application of a PVDF-based self-cleaning coating enhanced with ZnO NPs on aluminum panels with the stated aim of reducing maintenance requirements for the coating by increasing the level of hydrophobicity.

\section{Methods}

\subsection{Production of $\mathrm{ZnO}$ nanoparticles by continuous hydrothermal synthesis}

ZnO NPs are the key ingredient in the enhanced protective coating with self-cleaning properties. This section provides a brief description of the process of ZnO NP production using the large-scale technology developed under SHYMAN.

\subsubsection{The production process}

ZnO NPs are produced by continuous supercritical hydrothermal syntheses. A simplified flowchart of the process is given in Fig 1.

The hot and cold stream (precursor and deionized water) meet in the reactor to form NPs. The precursor for production in this case is zinc nitrate hexahydrate, which reacts under supercritical conditions according to the equation below.

$$
\mathrm{Zn}\left(\mathrm{NO}_{3}\right)_{2} \cdot 6 \mathrm{H}_{2} \mathrm{O}+2 \mathrm{KOH} \rightarrow \mathrm{ZnO}+2 \mathrm{KNO}_{3}+7 \mathrm{H}_{2} \mathrm{O}
$$

The temperature of the upstream flow of supercritical water into the reactor where the NPs are created is $400^{\circ} \mathrm{C}$. The post-processing steps include sedimentation and washing of the NPs, helping to increase the particle concentration and reduce impurities. Wastewater is then neutralized before it is discharged into sewage treatment.

The process of NP creation by supercritical hydrothermal syntheses in a specially designed reactor is detailed in Lester et al. ${ }^{2}$. Within the SHYMAN project the reactor was completely reevaluated to enable the production process to be scaled up. The productivity of the large-scale plant in Nottingham is envisioned to be $30 \mathrm{~kg}$ of $\mathrm{ZnO}$ NPs per hour. 


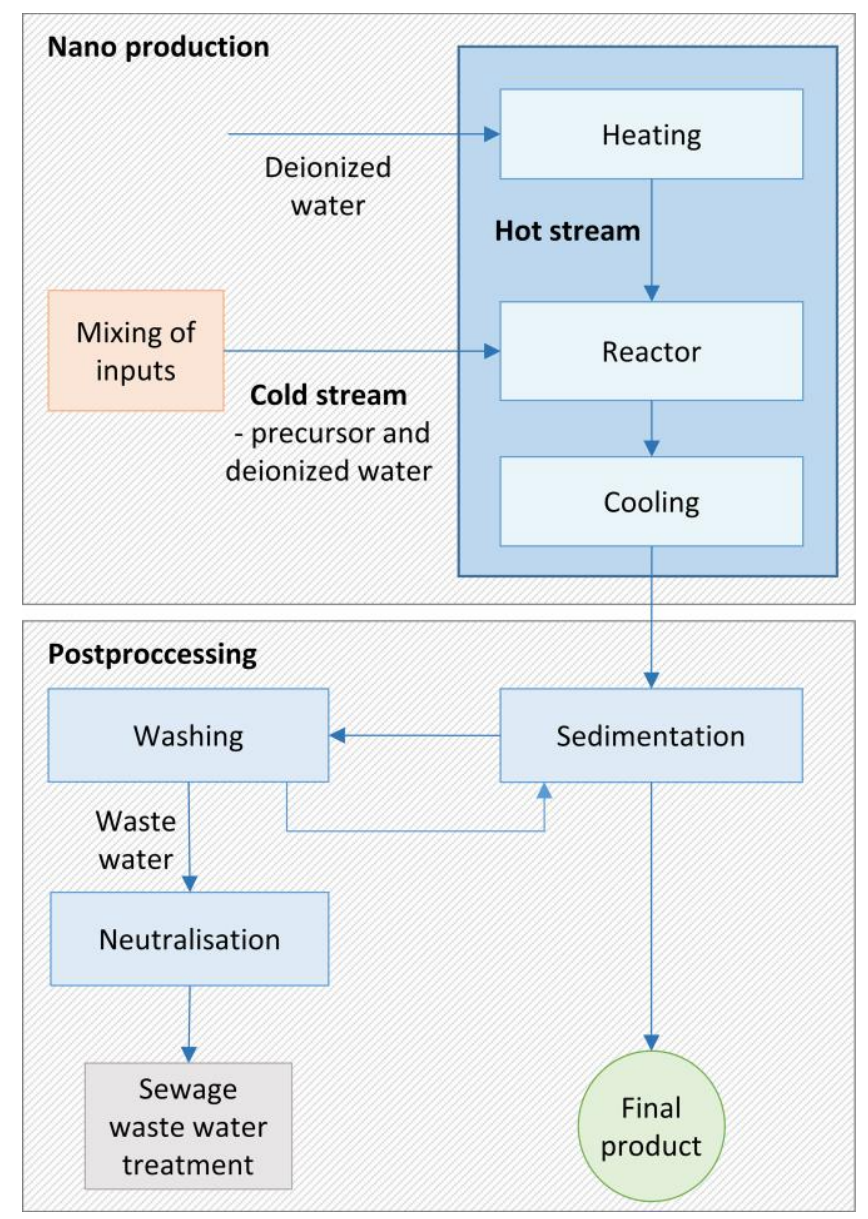

Fig. 1 The process of continuous supercritical hydrothermal synthesis with post processing steps (SHYMAN technology)

\subsubsection{ZnO NP characteristics}

The ZnO produced by SHYMAN technology is a high quality NP: The crystallite size distribution is $44.5 \pm 21 \mathrm{~nm}$; the specific surface area by gas absorption (SSA) is $36 \pm \mathrm{m} 2 / \mathrm{g}$; the XRD pattern shows the single phase nature of the sample as well as its hexagonal wurtzite structure (Fig.2a). The morphology of NPs is shown in Fig.2b; some particles are in the form of needles and serve as a nucleus for the next ones.

These high quality ZnO NPs have many potential applications in various branches of industry, including rubbers, pharmaceuticals, cosmetics, textiles, electronics and electro technology, and photocatalysis. In our study $\mathrm{ZnO}$ NPs are applied in coatings on metal panels in order to improve the level of hydrophobicity. 

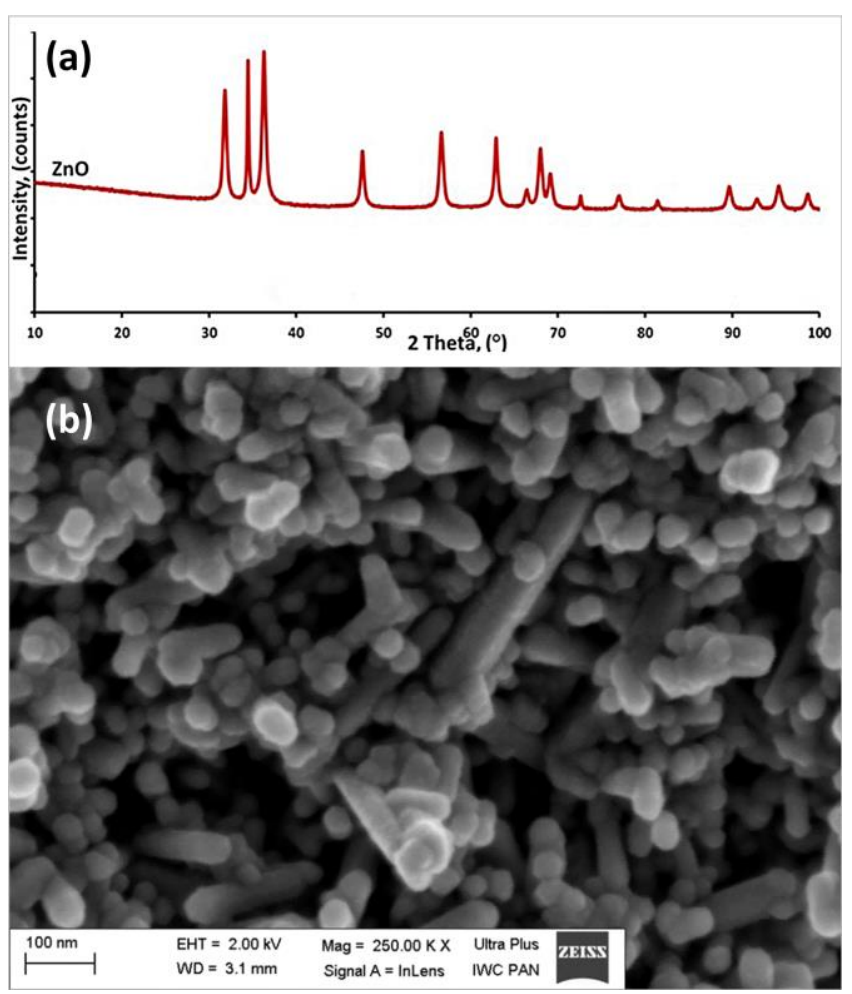

Fig. 2 XRD patterns and morphology of ZnO NPs

\subsection{LCA methodology}

As defined by ISO 14044:2006 Environmental management - Life cycle assessment - Requirements and guidelines, LCA represents a complex method for an evaluation of environmental impacts. LCA ${ }^{3,4,5}$ analyzes the whole life cycle of specified product from raw material acquisition to the product's end of life - "from cradle to grave". The LCA study consists of four phases: goal and scope definition, inventory analysis, impact assessment, and interpretation. Within the goal and scope definition phase the functional unit and system boundaries are defined. The second phase, inventory analysis, includes definition of system inputs and outputs, aggregation and evaluation of all resources, and quantification of the pollutant emission in relation to the functional unit. Life cycle impact assessment (LCIA) aims to describe, or at least to indicate, the impacts of the environmental loads quantified in the inventory analysis. SimaPro version $8.1 .1 .16^{6}$ connected to global life cycle inventory $(\mathrm{LCl})$ databases was used as a software tool for calculation of LCA results.

\subsection{Overview of LCA studies focused on coatings}

According to Reijnders ${ }^{7}$, information regarding the influence of NPs on environmental and economic impacts of self-cleaning products is limited. New LCA studies have been completed since the publication of the Rejinders paper, but few compare the environmental benefits of NPs with those of conventional products. Tab. 1 gives an overview of LCA studies for coatings containing various types of NPs. Nano-sized $\mathrm{TiO}_{2}$ makes an appearance in almost all of the studies as a coating enhancer. Available studies, however, show the following shortcomings: Some do not compare coatings with and without NPs (Pini $\left.{ }^{8,9}\right)$; NPs are not always added for their self-cleaning 
properties, but for other beneficial reasons (Hichier et al. ${ }^{10}$, Babizadeh and Hassan ${ }^{11}$ ); NP release is considered only in studies by Pini ${ }^{8,9}$ and Hichier et al. ${ }^{10}$ who references the characterization factor (CF) proposed by Salieri et al. ${ }^{12}$; and in other studies the release of NPs is not taken into account at all. The reliable data of NP production are missing in Liljenstrom et al..$^{13}$ study.

\begin{tabular}{|c|c|c|c|c|c|}
\hline $\begin{array}{l}\text { LCA } \\
\text { Study }\end{array}$ & Focus of the study & Functional unit & $\begin{array}{c}\text { Comparison of } \\
\text { product } \\
\text { with/without NPs }\end{array}$ & SCC properties & NP release consideration \\
\hline 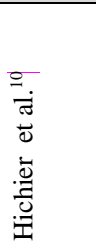 & $\begin{array}{l}\text { Facade coating } \quad \text { systems } \\
\text { containing } \\
\text { nanomaterials }\left(\mathrm{TiO}_{2}, \mathrm{Ag}, \mathrm{SiO}_{2}\right)\end{array}$ & $\begin{array}{l}\text { Protection of one square } \\
\text { meter of wall (indoor or } \\
\text { outdoor) over a period of } \\
80 \text { years }\end{array}$ & Yes & $\begin{array}{l}\text { No, NPs are added } \\
\text { to lengthen lifespan }\end{array}$ & $\begin{array}{l}\text { Yes, for } \mathrm{TiO}_{2} \\
\text { Based on CF for freshwater } \\
\text { ecotoxicity calculated by } \\
\text { Salieri et al. }{ }^{12}\end{array}$ \\
\hline 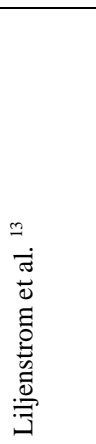 & $\begin{array}{l}\text { Maintenance of road safety } \\
\text { cameras coated with self-cleaning } \\
\text { nanofilm (Nano ProHard) } \\
\text { compared to the conventional } \\
\text { maintenance regime }\end{array}$ & $\begin{array}{l}\text { The maintenance of road } \\
\text { safety cameras in } \\
\text { Sweden to allow for an } \\
\text { acceptable speed camera } \\
\text { picture quality over one } \\
\text { year }\end{array}$ & $\begin{array}{l}\text { Yes, but } \\
\text { information about } \\
\text { production of } \\
\text { coating is missing, } \\
\text { Tetrachlorosilane } \\
\text { is proxy for the } \\
\text { active ingredients }\end{array}$ & Yes & No \\
\hline 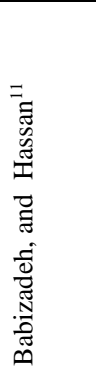 & $\begin{array}{l}\text { Glass coated with nano- } \mathrm{TiO}_{2} \\
\text { coating is compared with an } \\
\text { uncoated glass (float glass) on } \\
\text { residential windows with the } \\
\text { same specifications }\end{array}$ & $\begin{array}{l}\text { One square meter of } \\
\text { titanium dioxide coated } \\
\text { glass }\end{array}$ & Yes & $\begin{array}{l}\text { No, the } \\
\text { photocatalytic } \\
\text { performance of } \\
\mathrm{TiO}_{2} \text { is addressed } \\
\text { (reduction of } \mathrm{NO} \\
\text { and } \mathrm{NO}_{\mathrm{x}} \text { ) }\end{array}$ & No \\
\hline 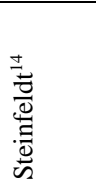 & $\begin{array}{l}\text { LCA of three alkyd paints with } \\
60 \% \text { of solvent; } 30 \% \mathrm{TiO}_{2} \times 10 \% \\
\text { nano } \mathrm{TiO}_{2} \times 20 \% \text { nano } \mathrm{TiO}_{2}\end{array}$ & - & Yes & - & - \\
\hline $\overrightarrow{0}$ & $\begin{array}{l}\text { Life cycle assessment of a nano } \\
\mathrm{TiO}_{2} \text { coating self-cleaning float } \\
\text { glass for private buildings. }\end{array}$ & $\begin{array}{l}1 \text { square meter of single } \\
\text { nano } \mathrm{TiO}_{2} \text { self-cleaning } \\
\text { coated float glass (size } \\
1500 \mathrm{~mm} \times 500 \mathrm{~mm} \times 4 \\
\mathrm{~mm} \text { ) }\end{array}$ & No & $\begin{array}{l}\text { Yes, and heat gain } \\
\text { during winter and } \\
\text { summer, and } \\
\text { reduction of NOx } \\
\text { and VOC were } \\
\text { involved }\end{array}$ & $\begin{array}{l}\text { Yes, emission of } \mathrm{TiO}_{2} \mathrm{NPs} \\
\text { during the application, use } \\
\text { and end of life }<100 \mathrm{~nm} \\
\text { introduced into the } \\
\text { Carcinogens impact category } \\
\left(\mathrm{Pini}^{8}\right) \text { and a new impact cat., } \\
\text { Carcinogens indoor, was } \\
\text { added }\end{array}$ \\
\hline
\end{tabular}




\begin{tabular}{|c|c|c|c|c|c|}
\hline$\stackrel{\Xi}{\Xi}$ & $\begin{array}{l}\text { Self-cleaning coating based on } \\
\text { nano } \mathrm{TiO}_{2} \text { polyurea resin applied } \\
\text { on an aluminum panel }\end{array}$ & $\begin{array}{l}1 \text { square meter of } \\
\text { aluminum panel coated } \\
\text { with nano } \mathrm{TiO}_{2} \text { polyurea }\end{array}$ & No & $\begin{array}{l}\text { Yes, benefits of } \\
\mathrm{TiO}_{2} \text { include } \\
\text { reduction of } \mathrm{NO}_{2} \\
\text { emissions, lower } \\
\text { survival ratio of } \\
\text { Escheria Coli, and } \\
\text { no maintenance } \\
\text { operations }\end{array}$ & $\begin{array}{l}\text { Yes, the characterization } \\
\text { factor was calculated: } 0.109 \\
\mathrm{kgC}_{2} \mathrm{H}_{3} \mathrm{Cl} / \mathrm{kg} \text { nanoTiO } \\
\text { (Damage to Human Health } \\
\text { caused by nanoTiO } \\
\text { emissions released in air, } \\
\text { particulates }<100 \mathrm{~nm} \text { ) }\end{array}$ \\
\hline 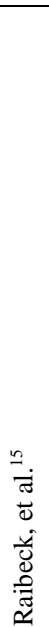 & $\begin{array}{l}\text { The study's goal is to compare } \\
\text { the life cycle of a self-cleaning } \\
\text { surface created using a chemical } \\
\text { coating (based on titanium) to } \\
\text { conventionally cleaned surfaces. } \\
\text { Mist cleaning (with water) of } \\
\text { coated machine parts is } \\
\text { compared with conventional } \\
\text { spray cleaning } \\
\text { (trichloroethylene). }\end{array}$ & $\begin{array}{l}1 \text { square meter of surface } \\
\text { area. For conventional } \\
\text { cleaning, the functional } \\
\text { unit becomes the } \\
\text { potential range of } \\
\text { volumes needed to cover } \\
\text { a surface area of } \\
1 \text { square meter. }\end{array}$ & $\begin{array}{l}\text { No, laser ablation } \\
\text { created templates } \\
\text { were used to } \\
\text { imprint small } \\
\text { scale surface } \\
\text { structures on } \\
\text { hydrophobic } \\
\text { material. }\end{array}$ & Yes & No \\
\hline
\end{tabular}

Tab. 1 Overview of LCA studies focused on coatings

\subsection{LCA study of self-cleaning coating}

\subsubsection{Goal, assumptions, system function, and the functional unit}

The goal of this study is the comparison of the environmental impacts of two protective coatings for aluminium sheets: one coating without and one with NPs. Hylar ${ }^{\circledR} 5000$, representing the advanced coating without NPs, is a PVDF-based resin used in the formulation of long-life architectural coating systems for metal elements of residential, institutional, commercial, and industrial building types. Made from UV-resistant fluoropolymer resins, PVDF coatings protect metal surfaces for over 35 years, while closely maintaining their original color and appearance (information from Solvay). ZnO NPs replace part of PVDF in Hylar ${ }^{\circledR} 5000$ in order to enhance its selfcleaning properties. The main difference in the new coating is its resistance to dirt accretion.

The life expectancy of both compared protective coatings was estimated by the manufacturer at 35 years. This assumption is consistent with estimations found in literature where life expectancy for nano coatings ranges between 20 and 40 years: 20 years without any maintenance for $\mathrm{TiO}_{2}$ coating on an aluminum panel $; 27$ years life expectancy for self-cleaning facade paint ${ }^{10}$ : and 40 years for glass nanoTiO coating $^{11}$.

The function of the coating is the protection of the metal sheet surface from adverse weather conditions and ensuring the surface cleanliness. For the purpose of this study, the functional unit is 1 square meter of protected metal panel for 1 year. 


\subsubsection{System boundaries, inventory data, and limitations}

System boundaries (Fig. 3) have been set to cover the whole life cycle of products.

(a)

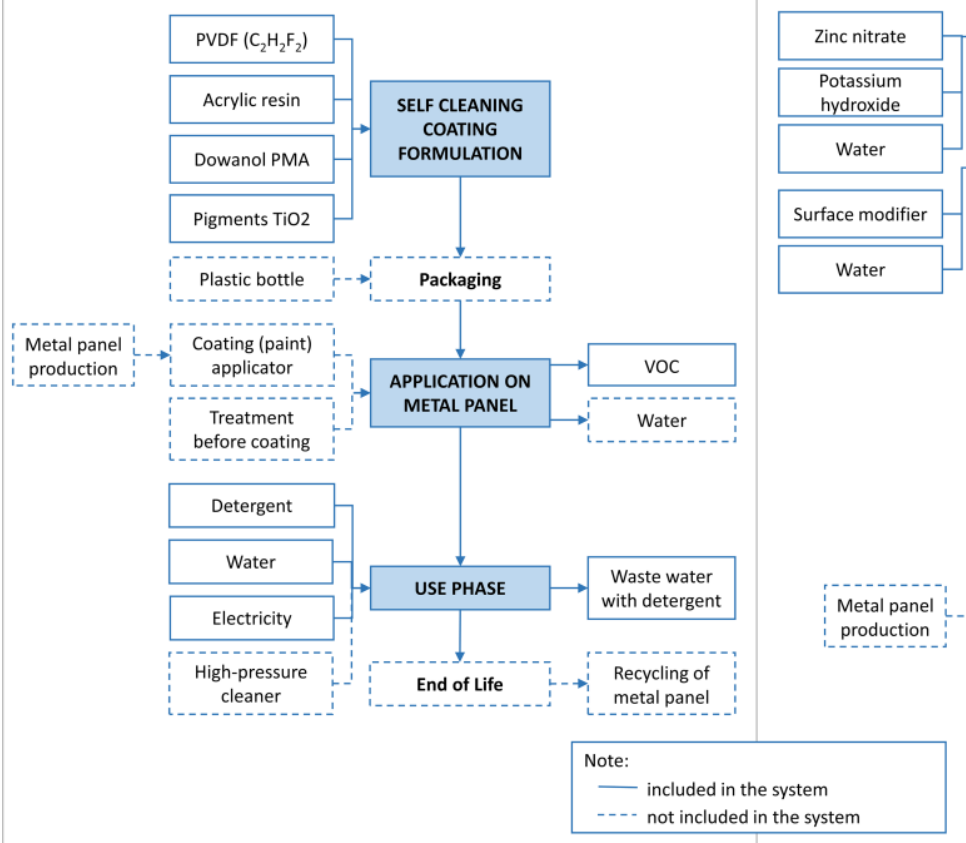

(b)

Fig. 3 Flow chart of SCC without (a) and with NPs (b)

Life cycle stages of SCC without NPs (Fig. 3a)

- Self-cleaning formulation - production of the self-cleaning coating, mixing of four components: PVDF, acrylic resin, Dowanol PMA, Pigments TiO2, energy use is also taken into account.

- Application on metal panel - energy consumption is included and VOC emissions are considered.

- Use stage - the self-cleaning coating without NPs is assumed to be cleaned once annually with water and detergent.

Life cycle stages of SCC with NPs (Fig. 3b)

- Production of nano ZnO by supercritical hydrothermal synthesis developed under the SHYMAN project.

- Treatment of NPs - before adding ZnO nanoparticles to the mixture they must be put through a treatment with a surface modifier.

- The self-cleaning formulation stage is almost the same as for coating without NP except that part of PVDF is replaced by ZnO NPs and more energy is used in the process of mixing particular compounds.

- Application on a metal panel is assumed to be the same as for coating without NPs.

- The use stage has no inputs and no outputs because a maintenance-free coating is envisioned.

Packaging, transportation (except NP packaging and transportation), treatment of aluminum panels before coating, and the end of life cycle stage are the same for both coatings and therefore are not involved in the LCA calculation. For the same reason the production and ultimate recycling of the aluminum metal panel are 
excluded from the assessment. Wear of the coating applicator is also excluded. Protection equipment is assumed to be the same for the coating with and without NPs.

\section{Data collection}

The primary data for metal panel coating production and application were provided by Solvay - HYLAR 5000 producer and nano-ZnO based SCC developer (communication from E leva, Solvay 2014). Data for large-scale nano ZnO production by supercritical hydrothermal syntheses was gathered under the SHYMAN project by the University of Nottingham. Data for the use phase of coating without NPs were estimated with help of calculation based on literature15, on the characteristics of the cleaning machine (3000W Karcher) and were confirmed by Solvay. Water use of $1.5 \mathrm{l}$, detergent use of $0.015 \mathrm{I}$, and electricity consumption of $0.0277 \mathrm{kWh}$ were assumed for one cleaning procedure for the functional unit of $1 \mathrm{~m} 2$. Other LCA data were taken from the SimaPro databases ${ }^{6}$ : Ecoinvent 3.

\section{Limitation of the data}

- No LCA data about PVDF are present in the SimaPro databases. According to Zackrisson et al. ${ }^{16} 50 \%$ Tetrafluoroethylene and 50\% Polyethylene, HDPE, granulate were used to replace the environmental influence of PVDF. This scenario for PVDF replacement was confirmed by Solvay representatives as acceptable.

- LCA data for the surface modifier Alcoxysilane that are not available in SimaPro databases ${ }^{6}$ were replaced by LCA data for Tetrachlorosilane, at plant from the SimaPro database ${ }^{6}$.

- Release of NPs were not taken into account in any life cycle stage for the following reasons: There is a lack of measures for assessing environmental impacts of NPs - characterization factors (CF) were calculated only for $\mathrm{TiO}_{2}$ NPs (Salieri et al. ${ }^{12}$ for freshwater ecotoxicity) and these CFs cannot be applied in the case of ZnO NPs because of its different behavior ${ }^{10}$. The number of NPs released in different life cycle stages is not known exactly. Gottschalk and Nowack ${ }^{17}$ estimated a release from 0-2 \% during manufacturing of ENMs. There is higher risk due mainly to the production and handling of dry powders. In the case of SHYMAN process, there is no NP release to the air, there is only negligible release of NPS during cleaning procedures and waste water treatment as it is described in literature ${ }^{18}$. As for NPs release during the use stage, Som et al. ${ }^{19}$ states that the initial results from Vorbau et al. ${ }^{20}$, on the abrasion of products incorporating nanomaterial, such as coatings incorporating $\mathrm{ZnO}$, show that no significant release of nanoparticles were detected and that the NPs were still embedded in larger particles.

\section{Results and discussion}

\subsection{LCA of ZnO NP production}

Detailed LCA results in individual impact categories using the ReCiPe21 method are shown in Fig. 4. Input chemicals-zinc nitrate and potassium hydroxide-have a significant influence on almost all impact categories. The heating/cooling stage also plays an important role in some impact categories, contributing $50 \%$ of the impact 
in the fossil depletion category, 30\% for climate change, and 53\% for ozone depletion. These impacts are caused primarily by natural gas consumption used for inflows heating. The wastewater treatment process accounts for one third of the essential contribution to environmental damage. The dominance of these three main contributors -zinc nitrate, the heating/cooling process, and wastewater treatment (WWT) - is evident in the single scores of the ReCiPe ${ }^{21}$ method (Fig. 5).

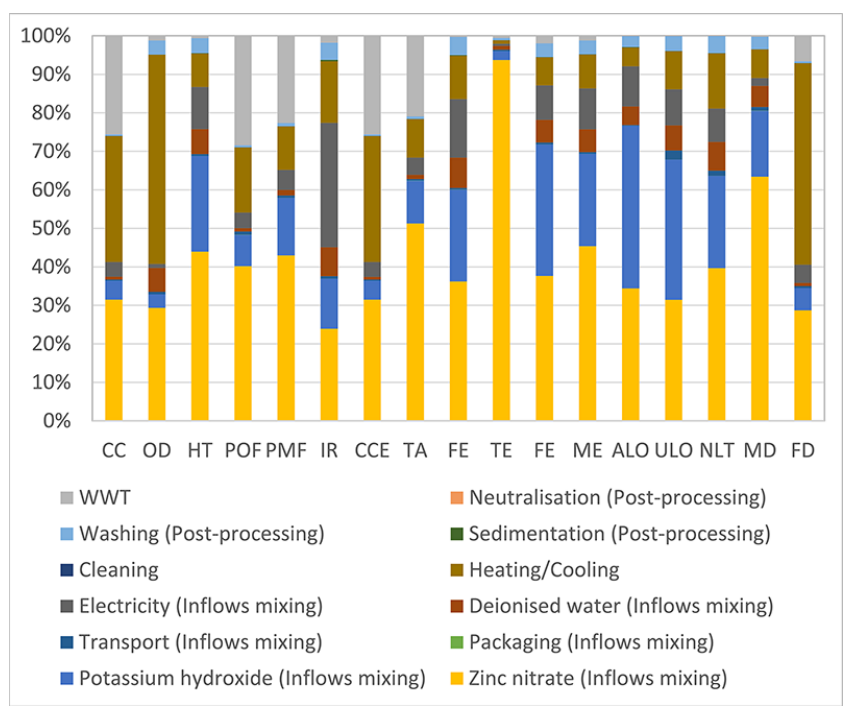

Fig. 4 LCA results of $1 \mathrm{~kg}$ of ZnO NPs (ReCiPe endpoint indicators: CC - Climate change; OD - Ozone depletion; HT - Human toxicity; POF - Photochemical oxidant formation; PMF - Particulate matter formation; IR - Ionizing radiation; CCE - Climate change ecosystems; TA - Terrestrial acidification; FE - Freshwater eutrophication; TE Terrestrial ecotoxicity; FE - Freshwater ecotoxicity; ME - Marine ecotoxicity; ALO - Agricultural land occupation; ULO - Urban land occupation; NLT - Natural land transformation; MD - Metal depletion; FD - Fossil depletion)

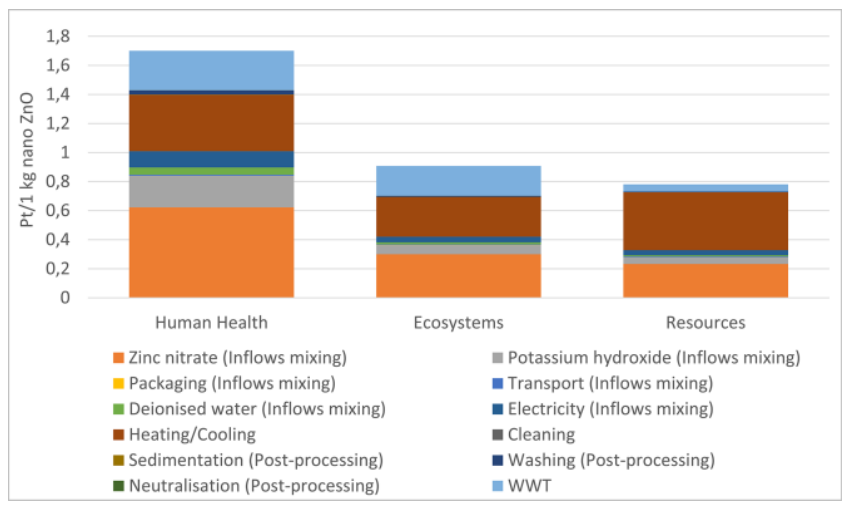

Fig.5 ReCiPe endpoint single score $-1 \mathrm{~kg}$ of ZnO NPs

\subsection{Comparison of LCA results - ZnO NPs versus PVDF}

Because treated ZnO NPs replace some of the PVDF in the modified self-cleaning coating, it is interesting to compare environmental impacts for these two substances. In Fig. 6 they are compared in two selected impact categories, cumulative energy demand (CED) and global warming potential (GWP). 


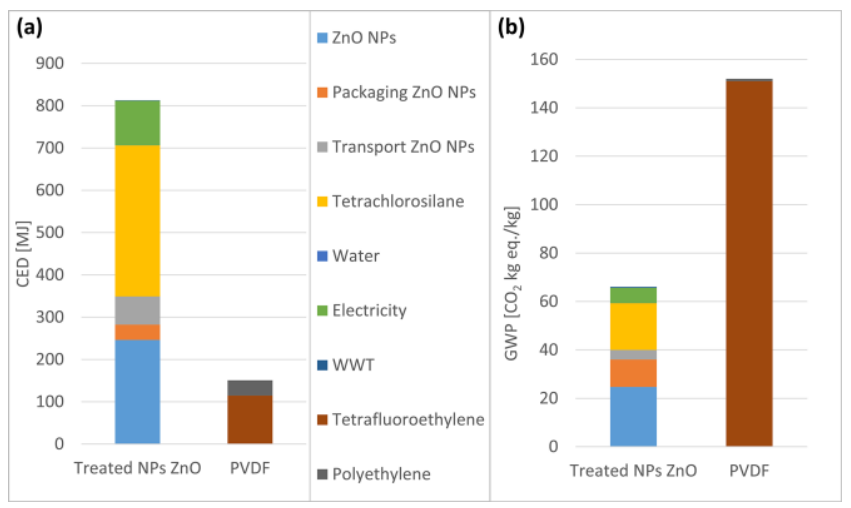

Fig. 6 CED (a) and GWP (b) for $1 \mathrm{~kg}$ of treated nano ZnO and $1 \mathrm{~kg}$ of PVDF with tetrafluoroethylene and polyethylene as proxy for PVDF16

For CED the influence of treated ZnO NPs is much higher than that of PVDF, $812 \mathrm{MJ} / \mathrm{kg}$ versus $150 \mathrm{MJ} / \mathrm{kg}$. The $\mathrm{ZnO}$ treatment stage has high impact because of the tetrachlorsilane that is used as a modifier. For GWP on the other hand PVDF performs significantly worse than treated ZnO NPs, with $152 \mathrm{CO} 2$ eq. kg versus $66 \mathrm{CO} 2$ eq. kg.

\subsection{Comparison of LCA results for coatings with and without NPs}

Fig. 8 gives a comparison of environmental loads for both coatings in different impact categories using the $\mathrm{ReCiPe}^{21}$ method throughout the whole life cycle. Coating with NPs performs better than coating without NPs in all impact categories. Fig. 7 illustrates the influence of different life cycle stages on selected impact categories for both coatings.

For the formulation stage the coating with NPs has slightly worse results in the impact categories of acidification potential, eutrophication potential, photochemical oxidation, and cumulative energy demand. In the other categories-global warming potential, ozone layer depletion and abiotic depletion-the coating without NPss cores worse than the coating with NPs due to the PVDF, which has a higher impact in these categories than treated ZnO NPs.

When the use stage is also considered, the coating with NPs shows a better environmental impact due to its maintenance-free use stage. The annual maintenance recommended for coating without NPs handicaps it in comparison with coating with ZnO NPs. It is of course the usage of detergent that represents the greatest influence in the use stage for coating without NPs with $70-85 \%$ of impact in some categories. Application phase has the lowest environmental impact in all of the impact categories. 


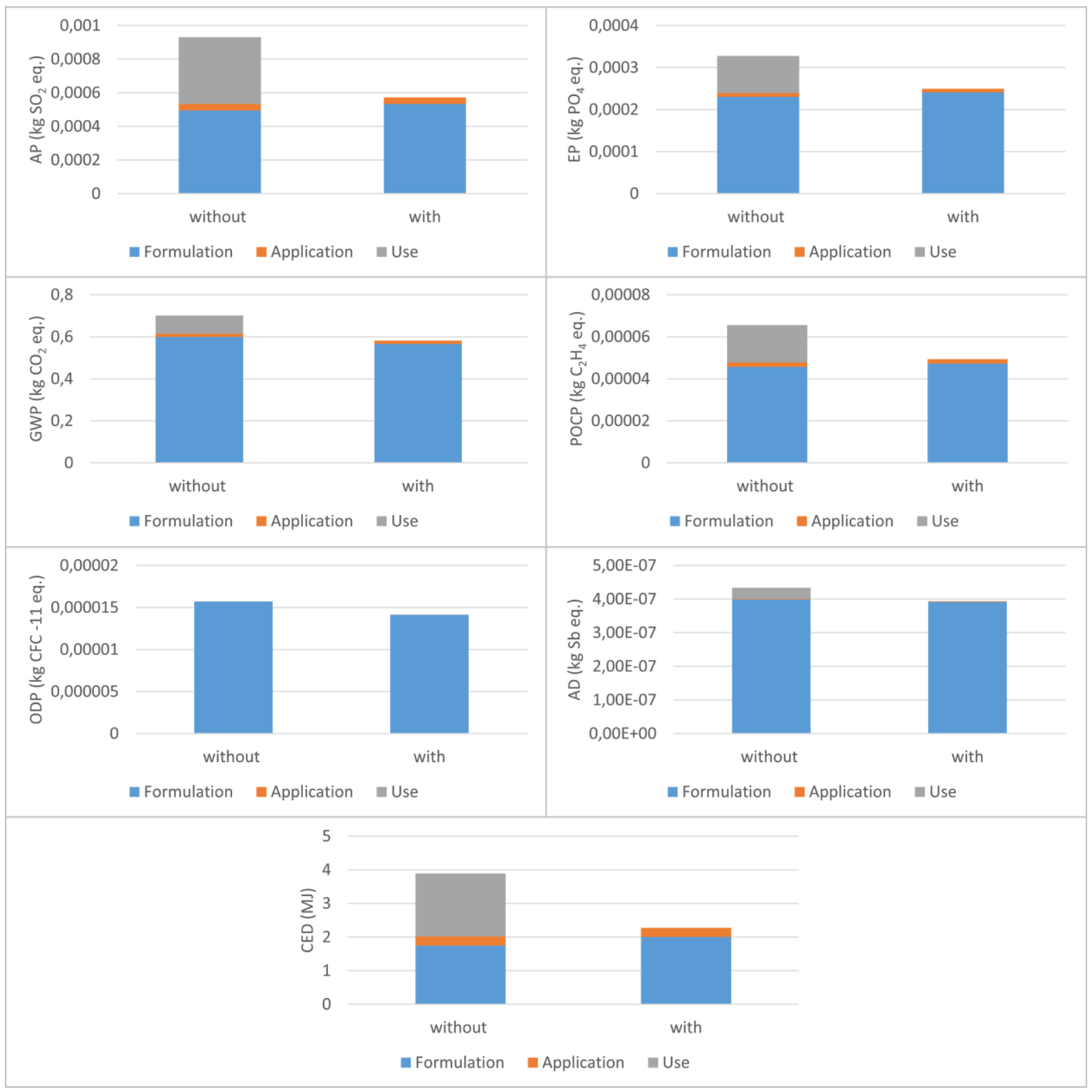

Fig. 7 Comparison of LCA results for coating with and without NPs (protection of $1 \mathrm{~m}^{2}$ for 1 year) - influence of different life cycle stages (EPD 2013 plus CED, EPD 2013 indicators: AP - Acidification potential, EP Eutrophication potential, GWP - Global warming potential, POCP - Photochemical oxidation potential, ODP Ozone layer depletion potential, AD - Abiotic depletion)

\subsection{Comparison of PVDF coatings without and with NPs with powder coating based on polyester}

In this section, the assessment of two alternatives to PVDF coatings is extended by a comparison with a common polyester-based powder coating, which provides a lower level of protection (thus more frequent maintenance and repainting of the coating during the defined time period is needed). The data for coating formulation and coating application on an aluminum panel were taken from the SimaPro database: Powder coating, aluminum sheet/RERU. The lifespan of powder coating is considered to be 10 years (www.ruukki.com). Cleaning three times a year with water and detergent is predicted, using the same amounts each time as for a cleaning of the non-NP coating.The PVDF non-NP coating has certain self-cleaning properties but with recommended annual 
maintenance. The removal of powder coating after its life expectancy period was not taken into account. The end of life of the aluminum panel is presumed to be the same for all coatings.

Fig. 8a shows the LCA results of a comparison of PVDF-based coatings with powder coating, which needed to be repainted and cleaned more frequently than PVDF coatings. In almost all categories SCC with NPs has the lowest environmental impact except in the ozone layer depletion category. Powder coating greatly exceeds the impact of the two PVDF coatings in almost all impact categories. From the normalized results (Fig. 8b) the significance of environmental impact is evident for climate change, human toxicity, and fossil depletion.

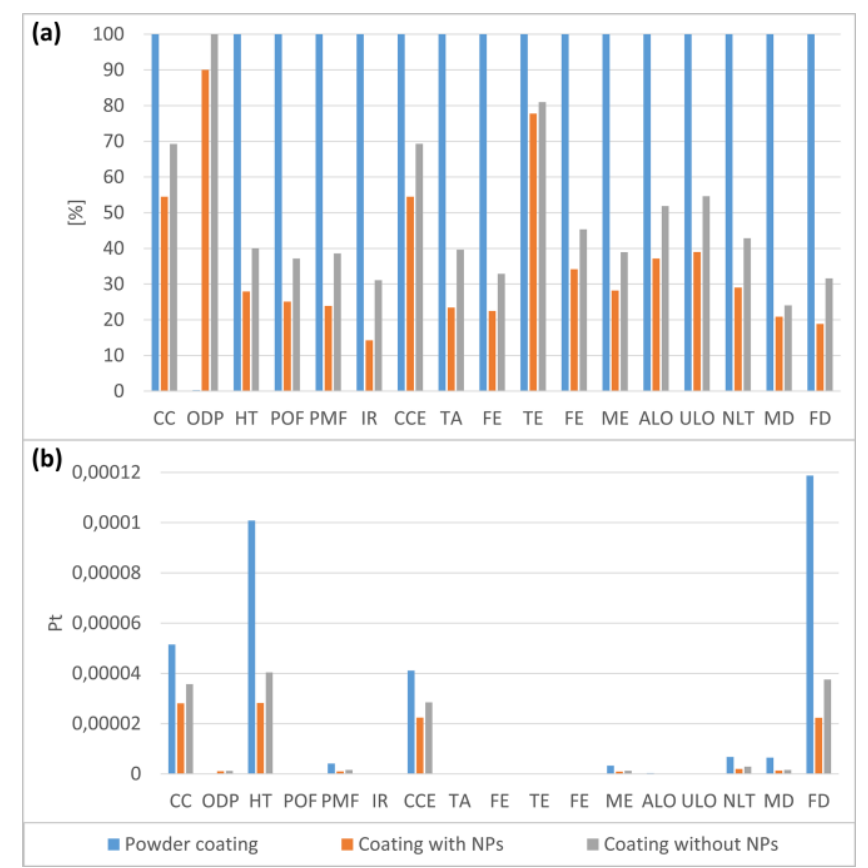

Fig.8 LCA comparison of PVDF-based coatings with powder coating - a) ReCiPe endpoint indicators b)Normalized ReCiPe endpoint indicators: CC - Climate change; ODP - Ozone depletion; HT - Human toxicity; POF Photochemical oxidant formation; PMF - Particulate matter formation; IR - Ionizing radiation; CCE - Climate change ecosystems; TA - Terrestrial acidification; FE - Freshwater eutrophication; TE - Terrestrial ecotoxicity; FE - Freshwater ecotoxicity; ME - Marine ecotoxicity; ALO - Agricultural land occupation; ULO - Urban land occupation; NLT - Natural land transformation; MD - Metal depletion; FD - Fossil depletion)

\subsection{Results summary}

As for $\mathrm{ZnO}$ NPs produced by supercritical hydrothermal synthesis the dominant contributors to environmental damage are zinc nitrate, the heating/cooling process, and wastewater treatment, accounting for almost $90 \%$ of the overall damage. The CED and GWP of ZnO NPs is augmented and exceeded by treatment with a surface modifier before use in the coating formulation.

Direct comparison of PVDF and treated ZnO NPs that replace part of PVDF in original Hylar 5000 coating displays that in CED category performs PDVF significantly better than treated ZnO NPs but for GWP category on the other hand treated ZnO NPs have much lower impact than PVDF. The same results are therefore characterizing the formulation stage. 
However, overall LCA results that consider the whole life cycle of the coatings show that the self-cleaning coating with NPs performs better than the coating without NPs in all assessed impact categories. This result is largely due to the elimination of environmental impacts within the use stage, where no maintenance is needed for the coating with NPs. This reduction clearly outweighs the slight increase of environmental impacts in some impact categories within the formulation stage that are associated with the use of ZnO NPs. In comparison with powder coating, PVDF coating with NPs performs significantly better in almost all impact categories except ozone layer depletion, but normalized LCA results show that the ODP category has low significance. Based on the results of this LCA study it can be concluded that the application of ZnO NPs brings clear environmental benefits not only in comparison with conventional powder paint, but also in comparison with advanced PVDF based coating.

\section{Acknowledgements}

This work is funded by the European Union's Seventh Framework Programme (FP7/2007-2013), grant agreement no. FP7-NMP4-LA-2012-280983, SHYMAN.

\section{References}

1. Project on Emerging Nanotechnologies; www.nanotechproject.org. Accessed 25 June 2014.

2. Lester, E.; Blood, P.; Denyer, J. D.; Giddings, D.; Azzopardi, B.; Poliakoff, M. Reaction engineering: The supercritical water hydrothermal synthesis of nano-particles. J Supercrit Fluids. 2006, 37, 209-214.

3. Guinee, J.B.; Gorree, M.; Heijungs, R.; Huppes, G.; Kleijn, R.; de Koning, A.; van Oers, L.; Wegener Sleeswijk, A.; Suh, S.; Udo de Haes, H.A.; de Bruijn, H.; van Duin, R.; Huijbregts, M.A.J. Handbook on life cycle assessment: Operational guide to the ISO standards. I: LCA in perspective. Ila: Guide. IIb:

Operational annex. III: Scientific background; Kluwer Academic Publishers: Dordrecht, Netherlands, 2002.

4. International Organization for Standardization. Environmental management-Life cycle assessmentPrinciples and Framework. Geneva, Switzerland: ISO 14040:2006, 2006.

5. International Organization for Standardization. Environmental management-Life cycle assessmentRequirements and guidelines. Geneva, Switzerland: ISO 14044:2006, 2006.

6. PRe Consultants. SimaPro 8.0.4 Ecoinvent inventory database v.3. Amersfoort, Netherlands: Simapro software, 2013.

7. Reijnders, L. The Environmental Impact of a Nanoparticle-Based Reduced Need of Cleaning Product and the Limitation Thereof. In Self-Cleaning Materials and Surfaces: A Nanotechnology Approach; Daoud, W.A., Ed.; John Wiley \& Sons Ltd: Chichester, UK, 2013; doi: 10.1002/9781118652336.ch11.

8. Pini, M. LCA of a self-cleaning coating based on nano TiO2-polyurea resine applied on an aluminium panel. NanoSafe, 15 November 2012, Grenoble, France; http://www.nanosafe.org/home/liblocal/docs/Nanosafe2012/presentations\%20orales/Session\%208/8a7_ Martina\%20Pini.pdf. Accessed 15 June 2014.

9. Pini, M. Life Cycle Assessment of a Nano TiO2 Coating Self-Cleaning Float Glass. Nanotech. 2013, 3, 728731. 
10. Hischier, R.; Nowack, B.; Gottschalk, F.; Hincapie, I.; Steinfeldt, M.; Som, C. Life cycle assessment offacade coating systems containing manufactured nanomaterials. J Nanopart Res. 2015, 17, 68-81; doi:10.1007/s11051-015-2881-0.

11. Babaizadeh, H.; Hassan, M. Life cycle assessment of nano-sized titanium dioxide coating on residential windows. Constr Build Mater. 2013, 40, 314-321; doi:10.1016/j.conbuildmat.2012.09.083.

12. Salieri, B.; Righi, S.; Pasteris, A; Olsen, S.I. Freshwater ecotoxicity characterisation factor for metal oxide nanoparticles: a case study on titanium dioxide nanoparticle. Sci Total Environ. 2015, 505, 494-502.; doi:10.1016/j.scitotenv.2014.09.107.

13. Liljenstrom, C.; Lazarevic, D.; Finnveden, G. Silicon based nanomaterials in a life cycle perspective, including a case study on self cleaning coatings: KTH - Royal Institute of Technology, US AB, Stockholm, Sweden, 2013; ISBN 978-91-7501-942-0; http://www.divaportal.org/smash/get/diva2:665233/FULLTEXT02.pdf. Accessed 15 July 2015.

14. Steinfeldt, M. LCA case studies of nanotechnology-based applications in the project NanoSustain. NanoSafe, 14 November 2012, Grenoble, France;

http://www.nanosafe.org/home/liblocal/docs/Nanosafe2012/presentations\%20orales/Session\%208/8a62012_11_14\%20NanoSafe\%20Grenoble\%2008a-6\%20LCA\%20UniHB\%20Michael\%20Steinfeldt\%20\%5B Mode\%20de\%20compatibilit\%C3\%A9\%5D.pdf, Accessed 18 July 2015.

15. Raibeck, L.; Reap, J.; Bras, B. (2008) Investigating Environmental Benefits of Biologically Inspired Selfcleaning Surfaces. 15th CIRP International Conference on Life Cycle Engineering 2008, Sydney, NSW, Australia; CIRP 2008:640-645; ISBN: 1877040673;

http://search.informit.com.au/documentSummary; dn=563883330209937;res=IELENG. Accessed 18 April 2015

16. Zackrisson, M.; Avellan, L.; Orlenius, J. Life cycle assessment of lithium-ion batteries for plug-in hybrid electric vehicles-Critical issues. J Clean Prod. 2010, 18, 1519-1529.

17. Gottschalk, F.; Nowack, B. The release of engineered nanomaterials to the environment. J Environ Monitor.2011, 13, 1145-1155.

18. Pini, M.; Rosa, R.; Neri, P.; Bondioli, F.; Ferrari, A.M. Environmental assessment of a bottom-up hydrolytic synthesis of TiO2 nanoparticles. Green Chem. 2014, 17, 518-531; doi: 10.1039/c4gc00919c.

19. Som, C.; Berges, M.; Chaudhry, Q.; Dusinska, M.; Fernandes, T.F.; Olsen, S.I.; Nowack, B. The importance of life cycle concepts for the development of safe nanoproducts. Toxicology. 2010, Volume 269, Issue 2, 160169.

20. Vorbau, M.; Hillemann, L.; Stintz, M. Method for the characterization of the abrasion induced nanoparticle release into air from surface coatings. J Aerosol Sci. 2009, 40, 209-21.

21. Goedkoop, M.J.; Heijungs, R.; Huijbregts, M.; De Schryver, A.; Struijs, J.; Van Zelm, R. ReCiPe 2008, A life cycle impact assessment method which comprises harmonised category indicators at the midpoint and the endpoint level, 3rd ed, report I: Characterisation, 6 January 2009; http://www.Icia-recipe.net. 